$\xi=2$

\title{
Prevalence of impacted canine among Yemen population in Sana'a city
}

\author{
Fuad L Al-Motareb ${ }^{1}$, Mohammed A Al-Labani1 ${ }^{1}$, Nabil M Al-Zubair ${ }^{1}$, Esam Dhaifullah ${ }^{2} *$ \\ ${ }^{1}$ Department of Orthodontics, Faculty of Dentistry, Sana' a University, Sana'a, Yemen \\ ${ }^{2}$ Department of Preventive Dental Sciences, Al-Farabi Colleges, Riyadh, KSA \\ *Corresponding author E-mail: dhaifullah02@gmail.com
}

\begin{abstract}
Objective: Impacted maxillary and mandibular canine is a frequently encountered clinical problem. The objective of the present study was to determine the prevalence of impacted canine in patients visiting an Orthodontic Clinic in Sana'a city, Yemen.

Materials and methods: Patients were examined in order to detect the impacted canines by radiographs. This study comprises data from randomly selected 5287 patients. Panoramic radiographs of 5287 were selected irrespective of sex, caste, nutritional and socio-economic status Angulation and depth of impacted canine were also assessed.

Results: Out of 5287 surveyed subjects, 188 patients (3.55\%) were determined to have canine impactions of whom 123 female and 65 male $($ Chi-square $=18.667, \mathrm{df}=1, \mathrm{P}=0.00001)$. Of those determined with canine impaction, 168 presents with impacted maxillary canines, 8 presents with the impacted mandibular canine and 12 present with impacted canine in both maxillary and mandibular arch. The difference was statistically significant (Chi-square $=157.362$, $\mathrm{df}=1, \mathrm{P}=0.0000)$. 138 subjects present with unilateral impaction, while the rest of the sample (50 subjects) present with bilateral impaction. Mesioangular impaction was found in 137 subjects (68.5\%) and only 3 subjects $(1.5 \%)$ demonstrated distoangular impaction.

Conclusion: Based on the study results, the canine impaction was reported in (3.55\%) of Yemeni population included in the survey. Most of the canine impaction occurs in maxillary arch being more prevalent in female and unilateral in mesioangular direction.
\end{abstract}

Keywords: Canine Impaction; Distoangular Impaction; Prevalence; Mesioangular Impaction

\section{Introduction}

Most of clinicians agree that permanent canines are important for both aesthetic and functional points of view and therefore, should be preserved whenever possible (Bishara SE et al 1976, p. 371). However, Dewell BF 1949, p. 79, mentioned that no tooth was more interesting to a developmental point of view than the upper cuspid, of all teeth it has the longest period of development, the deepest area of development, and the most conniving course to travel from its point of origin to full occlusion, which makes it vulnerable much longer to favourable or unfavourable environmental influences. It is rarely congenitally missing, and it is the final factor in securing contacting relations between all the teeth, as it has to prepare part of space by wedging action which it requires in the dental arch.

Wheeler considered the upper permanent canine to be of a great value since it is placed in the 'corner' of the mouth, the longest tooth with the longest route, supports the incisors and premolars and well anchored to the maxilla, of low susceptibility to caries and of high functional and aesthetic values (Wheeler RC 1974, p.48)

On the other hand, Tully \& Crver 1969, p. 23, mentioned that the un-erupted and displaced canine is quite a common problem, while Foster TD 1975, p. 39, stated that the permanent upper canine is probably the tooth which is most frequently developed in a wrong position. Kinaan BK 1981, p.149, reported that, the malposed canine forms the most frequent chief complaints in Iraq and in 1982 ; he found that $24 \%$ of orthodontic patients have their chief complain relating malposed canines (Kinaan BK 1982, p. 24).

Mitchell \& Carter 200, p. 231, considered the following factors to be the probable causative factors for the maxillary canine displacement: Displacement of the crypt, long path of eruption, shortrooted or absent upper lateral incisor, retention of the primary deciduous, canine and crowding.

Review of available literatures has been presented that most of the previous studies concentrated on the malposition of the upper canine. On the other hand, no information were found about the prevalence of impacted canine in Yemen. Therefore, the aim of present study was to establish a base data information about the prevalence of impacted canine in Yemen.

\section{Materials and methods}

The Ethics Committee of the Faculty of Dentistry, University of Sana'a, Yemen, approved this study. The study design and purpose were explained to all potential participants, who provided consent prior to participation.

The sample of this study was composed of 188 subjects (of Yemen origin) who were selected randomly from a population of 5287 . 123 subjects of the sample were females while the rest 65 subjects were males. Panoramic radiographs of 5287 were selected irrespective of sex, caste, nutritional and socio-economic status. Canines were considered as impacted when they remained below the jaw minimum two years after the respective mean age of tooth 
eruption. Age of the Patients included within the study was more than 15 years.

All radiographs were examined carefully by a single skilled dentist on a transparency projector under constant lighting conditions. All radiographs were determined for the number of impacted teeth in maxilla and mandible as well as both in male and female population.

In the present study, impacted canines were classified based on angulations and depths of the involved teeth. In terms of angulation, impacted canines can be classified as mesioangular, distoangular, vertical, or horizontal.

According to depth of the impactions (Figure1) was classified as Level A, Level B, and Level C as follows: (Yavuz MS, et al 2007, p. 78)

Level A. The crown of the impacted canine tooth is at the cervical line of the adjacent teeth.

Level B. The crown of the impacted canine tooth is between the cervical line and root apices of the adjacent teeth.

Level C. The crown of the impacted canines is beneath the root apices of the adjacent teeth.

When an impacted tooth was identified, the presence, absence, Inadequate space, resorption of root of lateral teeth, retention of deciduous canine, and development/eruption of the patient's other teeth were also assessed.

The statistical analysis was done using Statistical Packages for Social Science version 20 (SPSS Inc. Chicago, IL). The collected data was placed in tables, and the following statistical analyses were done:

1) Calculation of frequencies for nonparametric variables.

2) Chi-square test to examine any statistical association between the presence of impacted canines on one hand and gender and type of impaction on the other.

$\mathrm{P}$ levels of more than 5\% were considered statistically insignificant.

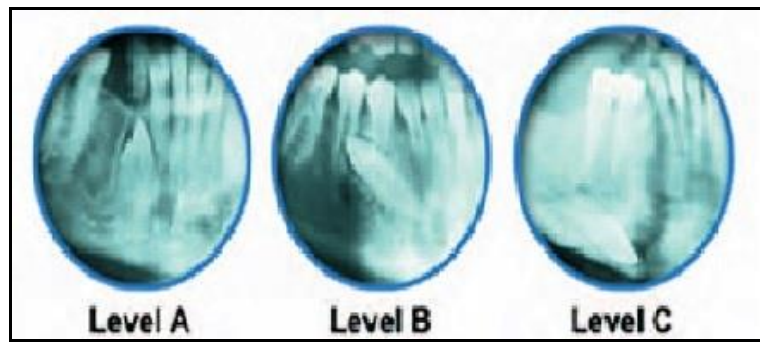

Fig. 1: Depth Classification of Impaction.

\section{Results}

The prevalence of impacted canine was higher in the maxillary arch $(3.18 \%)$ than in the lower $\operatorname{arch}(0.15 \%)$ as shown in table 1.

Table 1 also depicts the gender difference; the prevalence of impacted maxillary canine was higher in females $(2.1 \%)$ than in males $(1.06 \%)$, however the differences between them were statistically insignificant in the mandibular arch.

Table 1: Distribution of the Impacted Canine According to Gender

\begin{tabular}{|c|c|c|c|c|c|c|c|}
\hline Impacted & Female & & Male & & Total & & \\
\hline teeth & $\mathrm{N}$ & $\%$ & $\mathrm{~N}$ & $\%$ & $\mathrm{~N}$ & $\%$ & square \\
\hline $\begin{array}{l}\text { Maxillary } \\
\text { Canine }\end{array}$ & 112 & 2.1 & 56 & 1.06 & 168 & 3.18 & $18.667^{*}$ \\
\hline $\begin{array}{l}\text { Mandibu- } \\
\text { lar Canine }\end{array}$ & 4 & 0.07 & 4 & 0.07 & 8 & 0.15 & 0.0 \\
\hline $\begin{array}{l}\text { Maxillary } \\
+ \text { Mandibu } \\
\text { lar }\end{array}$ & 7 & 0.17 & 5 & 0.09 & 12 & 0.27 & 0.333 \\
\hline Total & 123 & 2.33 & 65 & 1.23 & 188 & 3.55 & $17.894 *$ \\
\hline
\end{tabular}

*Statistically Significant $\mathrm{P} \leq 0.05$.

According to type of impaction; more than two thirds of the sample (138 subjects) present with unilateral impaction, while the rest of the sample (50 subjects) present with bilateral impaction as shown in table 2 .

\begin{tabular}{|c|c|c|c|c|c|c|c|}
\hline \multirow{2}{*}{$\begin{array}{l}\text { Impaction } \\
\text { teeth }\end{array}$} & \multicolumn{2}{|c|}{ Unilateral } & \multicolumn{2}{|c|}{ Bilateral } & \multicolumn{2}{|c|}{ Total } & \multirow{2}{*}{$\begin{array}{l}\text { Chi- } \\
\text { square }\end{array}$} \\
\hline & $\mathrm{N}$ & $\%$ & $\mathrm{~N}$ & $\%$ & $\mathrm{~N}$ & $\%$ & \\
\hline $\begin{array}{l}\text { Maxillary } \\
\text { Canine }\end{array}$ & 124 & 2.35 & 44 & 0.83 & 168 & 3.18 & $38.095^{*}$ \\
\hline $\begin{array}{l}\text { Mandibular } \\
\text { Canine }\end{array}$ & 5 & 0.095 & 3 & 0.055 & 8 & 0.15 & 0.5 \\
\hline $\begin{array}{c}\text { Maxillary } \\
\text { +Mandibular }\end{array}$ & 9 & 0.215 & 3 & 0.055 & 12 & 0.27 & 3.0 \\
\hline Total & 138 & 2.6 & 50 & 0.945 & 188 & 3.55 & $41.191 *$ \\
\hline
\end{tabular}

* Statistically Significant $P \leq 0.05$.

Concerning the angulation of impacted canine; $68.5 \%$ of the sample present with mesioangular impaction, $21.5 \%$ present with vertical impaction, $8.5 \%$ present with horizontal impaction and $1.5 \%$ present with distoangular impaction as shown in table 3 .

Table 3: Distribution of the Impacted Canine According To Angulation

\begin{tabular}{llll}
\hline Angulation & No. of teeth & Percent & Chi-square \\
\hline Mesioangular & 137 & 68.5 & \\
Distoangular & 3 & 1.5 & \\
Horizontal & 17 & 8.5 & $218.32^{*}$ \\
Vertical & 43 & 21.5 & \\
Total & 200 & 100 & \\
\hline
\end{tabular}

* Statistically Significant $\mathrm{P} \leq 0.05$

Table 4 depicts the distribution of the impacted canine according to depth of impaction. Out of the 206 teeth unilateral and bilateral in the present study, the depths of 44 canines were classified as Level A $(21.4 \%), 103(50 \%)$ as Level B, and 59 of the canines were classified as Level C (28.6\%).

Table 4: Distribution of Impacted Canine According to Impaction Depth

\begin{tabular}{cccc}
\hline Depth of impaction & No. of teeth & Percent & Chi-square \\
\hline A & 44 & 21.4 & \\
B & 103 & 50 & $27.388^{*}$ \\
C & 59 & 28.6 & \\
Total & 206 & 100 & \\
\hline
\end{tabular}

* Statistically Significant $\mathrm{P} \leq 0.05$.

The anomalies associated with canine impaction were listed in table 5. It can be noticed that ectopic eruption was the most prevalent $(61.1 \%)$ followed by retention of deciduous canine $(51.5 \%)$, inadequate space $(28.2 \%)$. Root resorption of lateral teeth was rare $(6.3 \%)$. Our study found that incisor resorption to be more common in Maxilla than in Mandible.

Table 5: Occlusal Anomalies Associated with the Impacted Canine

\begin{tabular}{ccccccc}
\hline & \multicolumn{2}{c}{$\begin{array}{c}\text { Maxillary } \\
\text { Canine }\end{array}$} & \multicolumn{2}{c}{$\begin{array}{c}\text { Mandibular } \\
\text { Canine }\end{array}$} & \multicolumn{2}{c}{ Total } \\
\hline & $\mathrm{N}$ & $\%$ & $\mathrm{~N}$ & $\%$ & $\mathrm{~N}$ & $\%$ \\
$\begin{array}{c}\text { Ectopic } \\
\text { eruption }\end{array}$ & 115 & 68.4 & 0 & 0 & 115 & 61.1 \\
$\begin{array}{c}\text { Inadequate } \\
\text { space }\end{array}$ & 49 & 29.2 & 4 & 50 & 53 & 28.2 \\
$\begin{array}{c}\text { Resorption } \\
\text { of root of } \\
\text { lateral } \\
\text { teeth }\end{array}$ & 12 & 7.1 & 0 & 0 & 12 & 6.3 \\
$\begin{array}{c}\text { Retention } \\
\text { deciduous } \\
\text { canine } \\
\text { Total }\end{array}$ & 94 & 55.9 & 3 & 37.5 & 97 & 51.5 \\
\hline
\end{tabular}

\section{Discussion}

Treatment of malocclusion, at present is not a high priority in Yemen. Nevertheless, for future planning purposes, dependable and valid information about norms is desirable. Such information enables the establishment of practical guidelines for orthodontic diagnosis and treatment planning (Al-Zubair NM 2015, p. 50). From 5287 patients, $188(3.55 \%)$ subjects were determined to have canine impactions, of which 168 (3.18\%) subjects present 
with maxillary canine impactions, $8(0.2 \%)$ subjects present with mandibular canine impactions and $12(0.3 \%)$ subjects present with canine impaction in both maxillary and mandibular arch.

Maxillary canine impaction: It is a multifactorial dental anomaly commonly encountered in orthodontic practice, after the third molar, it is the most commonly impacted tooth (Dachi \& Howell 1961, p. 1165).

The incidence of canine impaction in the general population differs. In the present study, maxillary canine impaction was found in $3.18 \%$ of sample, which is higher than the findings of many other investigators (Jaciby H 1979, p. 143; Ericson \& Kurol 1986, p. 133; Thilander B, Myberg 1973, p. 13), which found the incidence to be between $0.8 \%$ and $2.8 \%$. These differences may be due to the difference in the race and the age of the sample of the previously mentioned studies, since most of them were done in European samples.

Our figure of maxillary canine impaction $(3.18 \%)$ was higher than that reported in the literature and related to Japanese, where the anomaly occurred in only $0.27 \%$ of the sample population. A study of a large series of full mouth dental radiographs among patients in the USA revealed a figure of $0.92 \%$ (Adrian BK 1998, p.139)

The etiology is multifold and can be related to the following factors: long tortuous path of eruption, tooth size and arch length discrepancies, arch width deficiencies, microform or absent lateral incisors, familial tendency, genetics, population differences, lack of resorption of the deciduous canine root, abnormal position of the tooth bud, presence of an alveolar cleft, and cystic or neoplastic formation (Zhong YL et al 2006, p. 483; Bishara SE 1992, p. 101; Brin I et al 1993, p. 104; Rimes RJ et al 1997, p. 79; Elefteriadis \& Athanasiou 1996, p. 257; Ericson S, Kurol 1987, p. 483) Impactions are twice as common in female patients (Chi-square $=$ $18.667, \mathrm{df}=1, \mathrm{P}=0.00001)$. This confirms the results of most published studies around the world (Alqerban A et al 2009, p. 764; Oliver RG et al 1989, p. 9).

Unilateral impaction was a significant finding at 133 of the subjects, more than 3 times the incidence of bilateral impaction These coincide with the finding of many investigators, while (Chung D et al 2011, p. 331), found that bilateral impaction was more frequent than unilateral impaction.

Mandibular canine impaction: (Ryan FS et al 2005, p. 70), reported that maxillary canine impaction is approximately 20 times more common than mandibular canine impaction.

Our data demonstrate that maxillary canine impaction was more common than mandibular canine impaction, since only 8 subjects out of 188 presents with mandibular canine impaction of whom 4 female and 4 male.

The difference was statistically significant (Chi-square $=157.362$, $\mathrm{df}=1, \mathrm{P}=0.0000$ ). If the subjects with both maxillary and mandibular canine impaction are included the number will be increased to 20 subjects, which constitute only $0.004 \%$ of the surveyed sample. Our findings are in line with those of Brown et al. (Brown LH et al 2005, p. 72) and (Shah RM et al 1978, p. 262), who have reported that impacted teeth are usually observed in the maxilla than in the mandible region.

On contrary to maxillary canine impaction, mandibular canine impaction distributed equally between right side and left side and there is no statistical significant difference between unilateral and bilateral impaction.

Angulation of impacted canine: Angulation has been evaluated as a predictor of canine impaction (Power \& Short 1993, p. 215), [28] found that, if the tooth was angled more than $31^{\circ}$ to the midline, the probability of impaction was increased. Our data reveal the predominance of mesioangular of canine impaction, since $68.5 \%$ of the whole sample presents with mesioangular of canine impaction, followed by vertical impaction $21.5 \%$, while distoangular canine impaction demonstrated in only $1.5 \%$ of subjects. (Chi-square $=218.32, \mathrm{df}=3, \mathrm{P}=0.00000$ )

Depth of impaction: Our data reveal that most of the surveyed Yemeni patient who present with canine impaction, the crown of the impacted canine tooth is located between the cervical line and root apices of the adjacent teeth, since about half of canines classified as level $\mathrm{B}$, while the other half distributed nearly equally between level A and level C. $($ Chi-square $=27.388, \mathrm{df}=2, \mathrm{P}=$ 0.00000113 ).

It was worth to mention that about $28.6 \%$ of the sample with impacted canine classified in level $\mathrm{C}$ where the crown of the impacted canines is beneath the root apices of the adjacent teeth which may replicate the difficulty of orthodontic treatment and should be taken into consideration during diagnosis and treatment planning. On another hand, $21.4 \%$ of the patients were classified in level A, where the crown of the impacted canine tooth is at the cervical line of the adjacent teeth which may reflect the possibility of surgical exposure and aligning to tooth to its position in the dental arch, further study is recommended to assess the location of impacted canine wither buccally or palatally.

Occlusal anomalies associated with the impacted canine: When an impacted tooth was identified, the presences of root resorption of lateral teeth, retentions of deciduous canine, ectopic eruption were also assessed. It can be noticed that ectopic eruption was the most prevalent $115(61.1 \%)$ followed by retention of deciduous canine $97(51.5 \%)$ Inadequate space $53(28.2 \%)$ and Root resorption of lateral teeth $12(6.3 \%)$

Resorption of the lateral incisors is very difficult to diagnose. Early diagnosis of impacted canine and root resorption might have further lessened complications during treatment, and the presence or absence of root resorption will be a factor in determining the treatment plan.

The maxillary lateral incisor root is the area most commonly affected by impacted canine. However, the retaining or resorption of the deciduous canine cannot be linked to incisor root resorption (Ericson \& Kurol 1987, p.332).

On the other hand, once direct tooth contact is present, the risk for root resorption may be increased. The anomalies associated with canine impaction were listed in table 5.

\section{Conclusion}

According to the results of this study, the prevalence of canine impaction in the selected population is estimated to be $3.55 \%$. Although maxillary canine impaction is more frequent than mandibular canine impaction. The prevalence of impacted maxillary canine was higher in females than in males, and it is statistically significant. Unilateral impaction is more common than bilateral impaction.

Mesioangular is the commonest pattern of impaction of the canine teeth followed by vertical impaction, horizontal and distoangular impaction. Our data has shown that the prevalence of maxillary canine impaction is a common dental anomaly. The early recognition of canine impaction is very imperative from a therapeutic point of view. There was no positive association between lateral incisor anomalies and maxillary canine impaction.

\section{References}

[1] Bishara SE, Kommer BD, Mc.Neil MH, Montgano LN, Young quist HW (1976). Management of impacted canines. Am J Orthod; 69: 371-387. https://doi.org/10.1016/0002-9416(76)90207-4.

[2] Dewell BF (1949). The upper cusped: its development and impaction. Angle Orthod; 19: 79-90.

[3] Wheeler RC (1974). Dental anatomy, physiology and occlusion. WB Saunders Co,P 23.

[4] Tulley WJ, Cryer BS (1969). Orthodontic treatment for the adults Chapter 1, John Wright and Sons Ltd, Bristol.

[5] Foster, TD (1975). A Textbook of orthodontics. Blackwell Scientific Publications, London.

[6] Kinaan BK (1981). Quantitative assessment of the occlusal features Brit J Orthod; 8: 149-56. https://doi.org/10.1179/bjo.8.3.149.

[7] Kinaan BK. The problem of malocclusion in Iraq (1982). Iraqi Dent J; 9: 24-8.

[8] Mitcheel L, Carter NE (2000). An introduction to orthodontics. Oxford University Press. 
[9] Yavuz MS, Aras MH, Büyükkurt MC, Tozoglu S (2008). Impacted Mandibular Canines. J Contemp Dent Pract (8)7:078-085.

[10] Al-Zubair NM (2015). Determinants Factors of Yemeni Maxillary Arch Dimensions, Saudi Dental Journal; 27: 50-54. https://doi.org/10.1016/j.sdentj.2014.08.005.

[11] Dachi SF, Howell FV (1961). A survey of 3,874 routine full-mouth radiographs: II. A study of impacted teeth. Oral Surg Oral Med Oral Pathol; 14:1165-9. https://doi.org/10.1016/0030 4220(61)90204-3.

[12] Jacoby H (1979). The "Balista spring" system for impacted teeth Am J Orthod;75: 143-51. https://doi.org/10.1016/00029416(79)90183-0.

[13] Ericson S, Kurol J (1986). Radiographic assessment of maxillary canine eruption in children with clinical signs of eruption disturbances. Eur J $133-40$. https://doi.org/10.1093/ejo/8.3.133.

[14] Thilander B, Myberg N (1973). The prevalence of malocclusion in Swedish school children. Scand J Dent Res; 81:12-20.

[15] Adrian Becker (1998), The Orthodontic Treatment of Impacted Teeth (Ed2), published by Martin Dunitz Ltd.

[16] Zhong YL, Zeng XL, Jia QL, Zhang WL, Chen L (2006). Clinical investigation of impacted maxillary canine. Zhonghua Kou Qiang Yi Xue Za Zhi; 41:483-5.

[17] Bishara SE. Impacted maxillary canines: a review (1992). Am J Orthod Dentofacial Orthop;101: 159-71. https://doi.org/10.1016/0889-5406(92)70008-X.

[18] Brin I, Becker A, Zilberman Y (1993). Resorbed lateral incisors adjacent to impacted canines have normal crown size. Am J Orthod Dentofacial Orthop;104: 60-6. https://doi.org/10.1016/08895406(93)70028-M

[19] Rimes RJ, Mitchell CN, Willmot DR (1997). Maxillary incisor root resorption in relation to the ectopic canine: a review of 26 patients. Eur J Orthod; 19:79-84. https://doi.org/10.1093/ejo/19.1.79.

[20] Elefteriadis JN, Athanasiou AE (1996). Evaluation of impacted canines by means of computerized tomography. Int J Adult Orthod Orthog Surg; 11:257-64.

[21] Ericson S, Kurol J (1987). Radiographic examination of ectopically erupting maxillary canines. Am J Orthod Dentofacial Orthop; 91:483-92. https://doi.org/10.1016/0889-5406(87)90005-9.

[22] Alqerban A, Jacobs R, Souza PC, Willems G (2009). In-vitro comparison of 2 cone-beam computed tomography systems and panoramic imaging for detecting simulated canine impactioninduced external root resorption in maxillary lateral incisors. Am J Orthod Dentofacial Orthop; 136:764 https://doi.org/10.1016/j.ajodo.2009.08.002.

[23] Oliver RG, Mannion JE, Robinson JM (1989). Morphology of the maxillary lateral incisor in cases of unilateral impaction of the maxillary canine. $\mathrm{Br} \quad \mathrm{J}$ Orthod;16:9-16. https://doi.org/10.1179/bjo.16.1.9.

[24] Chung D, Weisberg M, Pagala M (2011). Incidence and effects of genetic factors on canine impaction in an isolated Jewish population. Am J Orthod Dentofacial Orthop;139:331-335 https://doi.org/10.1016/j.ajodo.2010.06.023.

[25] Ryan FS, Batra P, Witherow H, Calvert M (2005). Transmigration of a maxillary canine. A case report. Prim Dent Care; 12: 70-72. https://doi.org/10.1308/1355761053695121.

[26] Brown LH, Berkman S, Cohen D, Kaplan AL, Rosenberg M (1982). A radiological study of the frequency and distribution of impacted teeth. J Dent Assoc S Afr; 37: 627-630.

[27] Shah RM, Boyd MA, Vakil TF (1978). Studies of permanent tooth anomalies in 7,886 Canadian individuals. I: impacted teeth. Dent J; 44: 262-264.

[28] Power SM, Short MB (1993). An investigation into the response of palatally displaced canines to the removal of deciduous canines. $\mathrm{Br}$ J Orthod; 20:215-23. https://doi.org/10.1179/bjo.20.3.215

[29] Ericson S, Kurol J (1987). Incisor resorption caused by maxillary cuspids: a radiographic study. Angle Orthod; 57:332-346. 